\title{
Generating a new image for cultural heritage: model for preserving the typical image of the traditional Turkish coffeehouse
}

\author{
N. Ayalp \& A. Müge Bozday \\ TOBB University, Turkey
}

\begin{abstract}
The aim of the study is to create a model for a reusing a specific cultural setting. Traditional Turkish coffeehouses are selected as a traditional environment. The coffeehouse, which has been used in Turkey since the sixteenth century, is one of the most significant places in the country's cultural heritage. Coffeehouses are one of the public spaces that represent the place identity of Turkish culture. During the Ottoman period, with their frequent use, people helped these places gain place identities. Moreover, not just the space but the ways in which people become socialized represent an intangible part of our cultural heritage. However, previous studies indicate that this cultural value has not been sufficiently transferred to the present day.

This study identifies the traditional Turkish coffeehouse as contributing to both tangible and intangible cultural heritage and generates a model for interpreting the coffeehouse in terms of a contemporary place identity. In order to do this, the concept of place, place identity, and social identity is discussed. Turkish coffeehouses are analyzed to identify and their typical spatial elements. In the conclusion, a model for preserving the typical image of the traditional Turkish coffeehouse is presented.
\end{abstract}

Keywords: traditional Turkish coffeehouses, place, place identity, social identity, typical elements in Turkish coffeehouses' interiors.

\section{Introduction: discussion of Turkish coffeehouses within a conceptual framework}

In order to safeguard a place that has a cultural value, it is not sufficient to discuss just its material attributes. When a place can be regarded as cultural 
heritage there may be many different dimensions in creating its intrinsic value. This study focuses on the interior space dimension of cultural heritage. An interior space creates a place that can represent our past, present and even our future. The interior space shapes the way we live. By designing appropriate spaces, a designer can influence whether a culture value survives or becomes lost in peoples' memory. In a way, the designer is able to crystallize the cultural value, or help it survive with contemporary living habits. As Hyung Yu defined the cultural setting, "the heritage setting potentially plays a significant role as a specific social space within which individuals are able to conceive, define and reconstruct elements of national consciousness" [1].

The Turkish coffeehouse is a place that represents the Turkish socio cultural identity, and was the first widely used public space of our culture. Coffeehouses have been present in Turkey for approximately 500 years, during which time drinking coffee became a way of socializing in Turkish culture. Historically, there were different locations within an Ottoman palace for serving and drinking coffee and special rituals developed related to drinking coffee. UNESCO defines intangible cultural heritage from many different aspects, such as "as a process and practices rather than end products", defined as "sources of identity, creativity, diversity and social cohesion" [2]. Within Turkish culture, drinking coffee is a form of social cohesion that has represented our identity for 500 years. Not just with its material value, but by setting and defining form of socialization, it also represents intangible cultural heritage of Turkish culture. In other words, through its social value, the coffeehouse also gains intangible value. Today both intangible and tangible cultural elements have lost their value and meaning.

Observed from this perspective, coffee, which has been in continuous use in Turkey from the sixteenth century until now, can be seen as an element of the country's cultural heritage. Typical Turkish coffee making and presentation techniques, though they have evolved over time, have also come down to the present day without interruption. Coffee was introduced to Turkey by the Governor of Ethiopia, Ozdemir Pasha, with the Ottoman conquest of Egypt and Hedjaz in the 16th century. According to a more precisely dated source, Muslim merchants brought coffee into the Ottoman Empire in 1517 via Yemen, Jizyah, Cairo and Alexandria [3]. By the 1600s, coffee was widely drunk in every corner of the empire. According to Evliya Celebi's Travel Book, in 1630 there were 55 coffeehouses in İstanbul alone. Several different types of coffeehouses have emerged over time. Some are reading houses (kıraathane), janissary (yeniçeri) coffeehouses and live entertainment (semai) coffeehouses.

Coffeehouses have also emerged as "interior spaces" over time, and have continued as such until today. Therefore, these spaces have as much intrinsic value to Turkish culture as coffee itself.

This study aims to develop a model for safeguarding for this social value, including its tangible and intangible components. From an interior architectural perspective, the study sets the typical features of the coffeehouse and discusses the dimensions to create a new model to preserve this value in contemporary living conditions. 


\section{Examination of interior spaces of Turkish coffeehouses}

The seating arrangements in coffeehouses are not so different from those of the sitting or guest rooms in an Ottoman mansion. Plan diagrams of coffeehouses reveal the same centric spatial understanding as that which is at the heart of the Ottoman Era's domestic sitting rooms.

Within the scope of this study, many coffeehouses in different provinces of Turkey were examined, and historical sources were used to examine defunct coffee shops. The study findings indicate that the coffeehouse is a reflection of the architectural style of the Ottoman period. In interior space, Ottoman architecture manifests itself in intensive ornamentation. Especially within interior spaces of those identified as city coffeehouses, intensive Ottoman stylistic effects are observed, both in the seating arrangement and the accessories used in interior space.

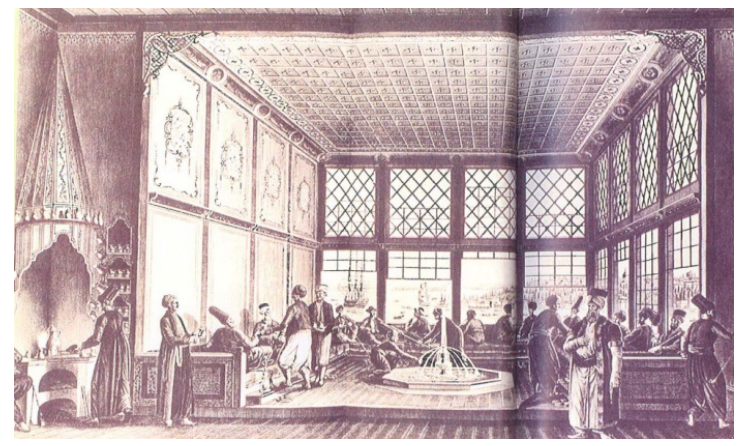

Figure 1: Ottoman coffeehouse in $18^{\text {th }}$ century [3].

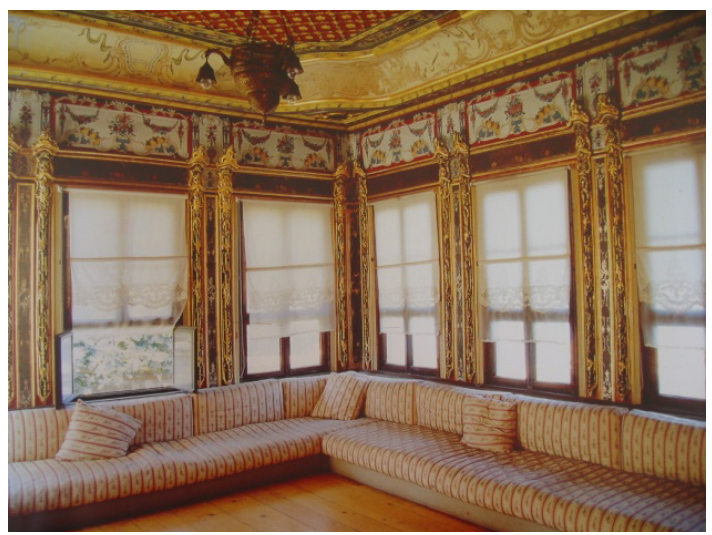

Figure 2: A view from Konak sitting room in Bosporus (Akşit Archive, 1996). 
Looking at the pictures of coffeehouses above, it is seen in the planning that there is a central pool, faced by wooden bedstead seating units placed around the walls. This layout was convenient for coffeehouse customers to maintain strong communication. The intensive cedar decoration used in the interior space and central pool reflect contemporary Ottoman aesthetic values.

According to Heise, the coffeehouse owner's finances determined whether or not elements such as pools were present [6]. The wooden bedstead seating unit was a typical accommodation seen in each coffeehouse. A top Divan was present in a corner outside the common sitting area. The stove was in another corner, outside the central place. In other words, different functions were placed at the perimeters in a space designed in a centripetal order.

A common feature of coffeehouses was that interaction between interior and external spaces was strong. A permeable interior and exterior space relationship was created with the help of large openings and seating that spread out to the gardens in the exterior space.

In the coffeehouse examples given above, we note that the coffeehouse was occasionally located in exterior space. Especially in Istanbul, coffeehouses were built in locations with breathtaking panoramic views.

Evaluating the elements in interior space, it is seen that columns are one of the most highlighted decorative elements. These columns, generally found in open areas in interior space, are intensively decorated with ornaments. The coves connecting these columns to each other, and the capitals and bases of columns, are the most elaborately decorated parts of the columns

In terms of the interior decor of coffeehouses, one of the most important decorative elements is the stove. The stove is located in an open area and may also serve a storage function; the cupboards and shelves surrounding it are the most functional decorative elements in a coffeehouse. The stove, shelves and cupboards in which coffee pots and cups are stored work together as a single unit. Coffee and coffee services are made in this unit.

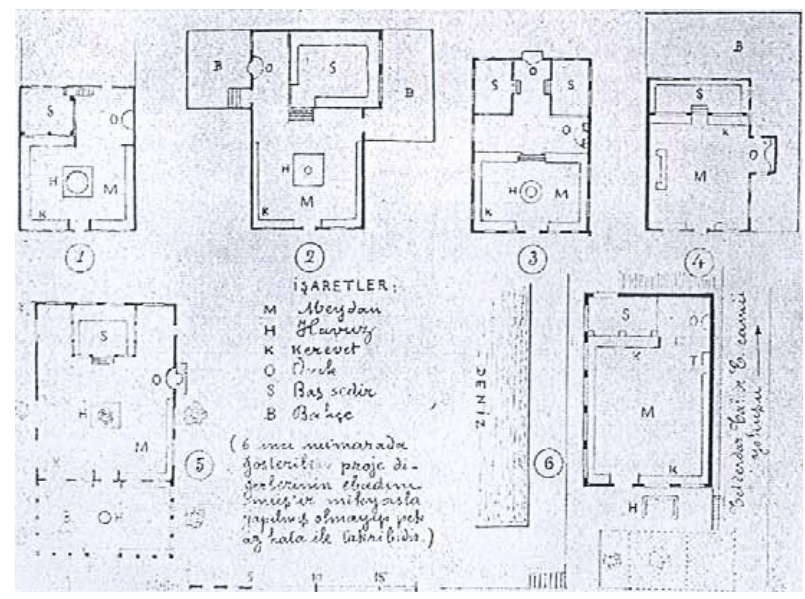

Figure 3: Interior space plan schemes in coffeehouse [5]. 


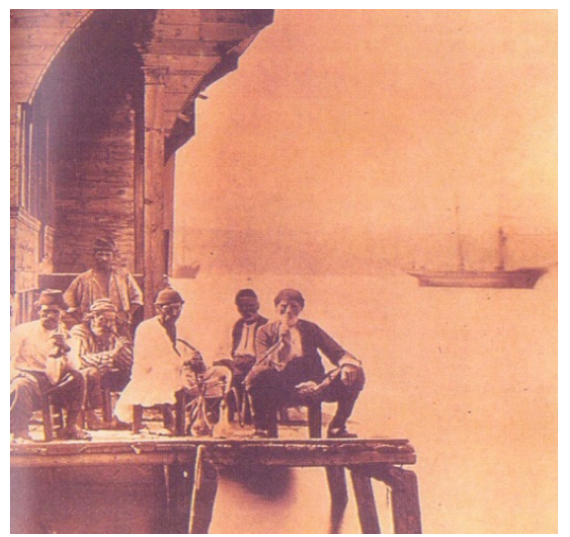

Figure 4: $\quad$ Exterior space view of Ottoman coffeehouses [3].

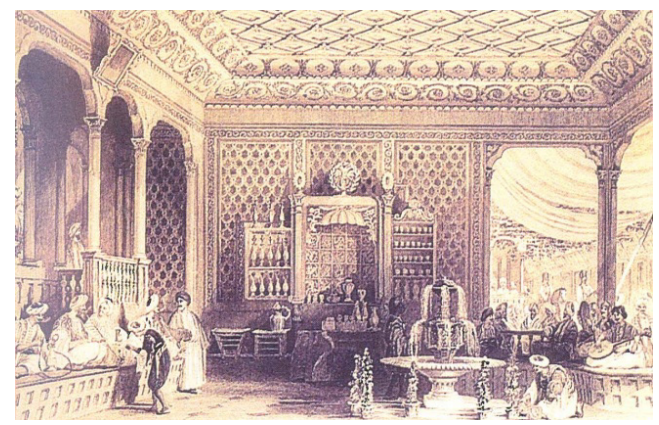

Figure 5: $\quad$ Coffeehouse column joist ornaments $1[3,5]$.

Despite some differences between coffeehouses, stoves are mostly elements decorated with intensive ornaments. In addition, stoves were positioned to dominate the interior space. On both sides of the stove, there are shelves in which coffee cups and other materials are stored [3]. The stove is the place where only coffee is cooked in the interior space and a decorative element to which many different meanings were attributed. It is also an indicator of the prestige levels of the coffeehouse's customers.

Divans are another important ornament element. The wooden bedstead sitting unit was the same as that used in an Ottoman guest room's seating arrangement. Chairs were not used in Ottoman times. This type of seating, also referred to as a wooden bedstead, was a pillowed and cushioned place to sit, 20 or $30 \mathrm{~cm}$ higher than the floor. Divans used externally were covered with wicker.

Another important decorative element in interior space is the pool. Water was part of coffeehouses because of its pacifying effect and coolness. Pools were used in coffeehouses with both functional and aesthetic goals. These intensively decorated pools were an effective decorative element in the interior space. 
There have also been changes over time in the appearance of coffeehouses, in line with the changing social structures. However, the nationalistic movements that emerged in Europe during the Second World War period also started to have an effect in Turkey. During this period, the early 1940s, national values gained prominence in architectural design. A synthesis was forming which was national and yet could meet the requirements of the era. This was independent of any pursuit of an "international" style. International style is an architectural movement that started in 1920s and aimed to develop a universal architectural expression. Thus, coffeehouses reformed with influences based on their past configurations. However, by the 1950 s various socialization spaces other than coffeehouses started to open, including patisseries, cafes and restaurants. These new types of spaces affected the usage of the coffeehouses.

With all of these complex social changes, coffeehouses became areas of socialization that were behind the times, failing to keep up with Turkish society in general. Coffeehouses cannot adapt to new consumption patterns and the fast pace of urban life. Traditionally, people would spend their time in coffeehouses for chatting, and in get know with each other. Especially with the effect of mass consumption, shopping malls have become the favorite setting in which people spend their leisure time. This is a time not for socializing, but actually for consumption. Today, coffeehouses are still not able to keep up with these new forms of socialization. However, a limited number of coffeehouses, used for touristic purposes, have a comparatively broader customer base than the others.

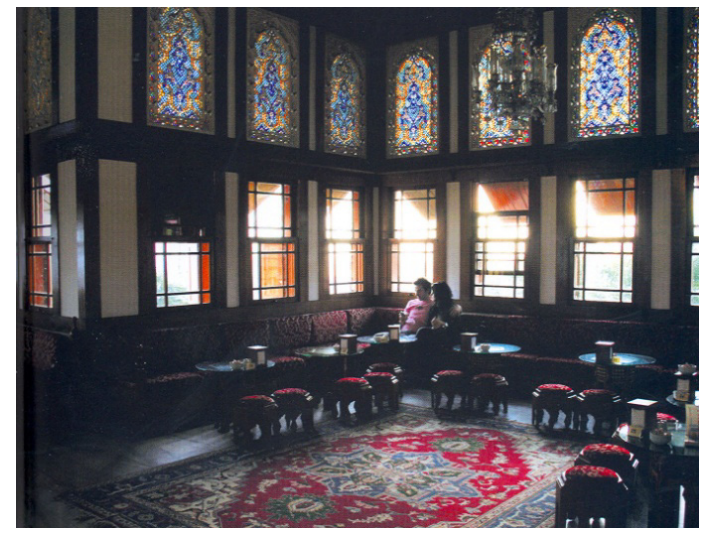

Figure 6: Examples of coffeehouse wooden bedstead seating elements from the present day [4].

\section{Typical elements in Turkish coffeehouses}

It is observed that these socialization places, used for such a long period of time, created their own identities. Looking at existing examples in the light of this historical information, although functionality may differ, repeated characteristics 
can be observed in the configuration of the interior spaces of the coffeehouses. These typical characteristics are:

- A holistic interior space set up in a space configuration

- Permeable interaction of interior and exterior space

- Typical decor elements;

- Stove unit (set up together with the serving and storage area around it)

—Wooden bedstead seating units

-Use of wicker stools

These typical elements are vital in users experience in a way that these typical elements reflect an image in the users' cognition. The cognitive process is formed by traditional types that are shaped through history. According to Schutz, people perceive the world through types and these types structured our cognitive schemes [7]. From this point of view, Auburn and Barnes summarize the approach as follows:

“the person's representation or stock of knowledge of the world, first, is social in that its typified content arises in and through the community and its history. Furthermore, typification is underpinned by language, or more precisely the "vernacular of the collectivity'...". [8]

By setting the typical elements of the coffeehouses, the study aims to create a contemporary image for his element of Turkish cultural heritage. The traditional Turkish coffeehouse can be regarded as a form of cultural heritage since it has a typical space understanding. These typical elements are fundamental in representation of a cultural place identity. In further sections, a model for the representation of cultural heritage will be introduced in the context of coffeehouse.

\section{Model for design proposal}

Based on the discussion above, it is apparent that Turkish coffeehouses are a part of the country's cultural heritage; in other words, they constitute a cultural value. However, previous studies indicate that this cultural value has not been sufficiently transferred to the present day. Due to problems arising from their inability to adequately adapt to modern living conditions, the use of traditional coffeehouses by city dwellers has been limited. Thus this space, which used to encompass the concept of place for earlier generations, lost its particular characteristics.

The formal and fundamental effort required to address this problem depends on the designer being able to achieve a design that incorporates cultural values at the image construction phase. The elements that constitute the typical characteristics of the traditional Turkish coffeehouse, as established above, need to be included at the base-level of the design. That way, a unique type of design at a national or international level could be achieved. 
In addition to certain conditions that need to be taken into consideration in the formation of the coffeehouse image, important points that influence the acceptance of the designer in general must also be considered. One of the most important points is that the design should adequately meet user requirements, as customer satisfaction is a major factor in the repeated use of the space. It is important for the space to meet the user needs in an ergonomic sense.

Another element in creating a new coffeehouse image is to realize that it must take on contemporary conditions and forms. The image should not simply replicate the past, and not simply mimic the existing characteristics in a modern design. Instead of exactly applying certain forms used in the past, it is important to convey these by way of an abstract and contemporary presentation. In other words, the designed interior space needs to be an interpretation, which conveys the unique values of the past but reconfigures them in the light of the present.

The design of coffeehouse interior space must be adapted to modern utility requirements. The space must be configured for a contemporary presentation. Modern eating and drinking patterns must be taken into account in setting up the space in order to increase its utility.

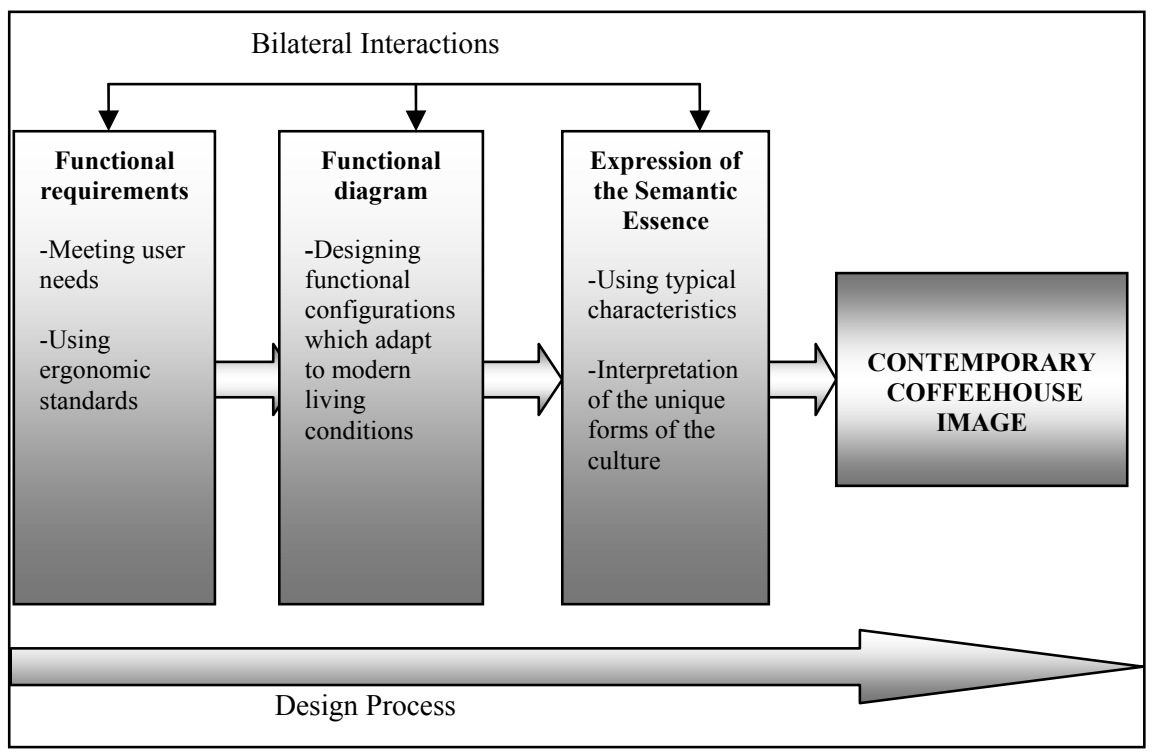

Figure 7: Contemporary coffeehouse image formation.

The above model is the phased expression of the coffeehouse image formation, providing a systematic presentation of the proposed recommendations. The first phase is presented as the functional requirements. It expresses the need to offer a working configuration that adapts to modern living conditions once functional requirements are completely fulfilled. It emphasizes the need to achieve culturally unique semantic content through the characteristics typical of the coffeehouse's interior space after these phases. It is suggested that, 
in this way, a contemporary coffeehouse image can be achieved. Moreover, creating a contemporary setting for the coffeehouse forms the basis to safeguard the intangible parts of this cultural heritage, especially the way is which people socialize.

\section{Conclusion}

In the past, the formation of certain concepts, which were shaped by the physical and psychological connections between the individual and the environment, were observed between the coffeehouses' interior spaces and their users. Today, coffeehouses can still be much more than just a space for their customers. These spaces can help in safeguarding the traditional forms of socialization within our own culture. This intangible cultural heritage can be preserved through preserving this space. Moreover, preserving this space does not mean to crystallize it or to make it into a place that is only observed as a curiosity and so becomes irrelevant to interaction. Proposing a contemporary model for this place can enable this space to encompass these differing aspects of intangible cultural heritage. UNESCO claims that, "to be kept alive, intangible cultural heritage must be relevant to its community, continuously re-created and transmitted from one generation to another" [2].

It must be understood that coffeehouses already have a cultural value of their own. Furthermore, it is certain that this unique value helps each one maintain an identity. In discussing the formation of an image, It is important to understand how this place identity is formed. In new UNESCO conventions, intangible cultural heritage is considered as an "essential factor for the preservation of cultural identity and diversity" [9]. This study discusses the importance of creating a new identity with the help of past values. Both the material parts and the social interaction in the space constituted a cultural identity. The Turkish coffeehouse contains both intangible and tangible parts of cultural heritage. The aim of this discussion is to reinterpret place in order to catch up with contemporary forms of living. This study suggests a way to protect these values and transfer them to new generations.

\section{References}

[1] Hyung Yu, P., 2009 'Heritage, Tourism, and National Identity: An Ethnographic Study of Changdeokgung Palace' Kore Journal 49:4 pp 163186.

[2] "Safeguarding without freezing" UNESCO Intangible Heritage 2003 Conventions http:// www.unesco.org/culture/ich/

[3] Evren, B., 1996. Eski İstanbul Kahvehaneleri. (İstanbul: Milliyet Yayınları)

[4] Eczacıbası, E., 2006. Kahvehaneler. İstanbul: Eczacıbaş1.

[5] Süheyl, Ü, 1963. "Türkiye'de Kahve ve Kahvehaneler" Türk Etnografya Dergisi. Ankara: Türk Tarih Kurumu.

[6] Heise, U. 2001, Kahve Kahvehaneler. Ankara: Dost. 
[7] Schultz, N. "Genius Loci: Towards a Phenomenology of Architecture", Rizzoli.

[8] Auburn, T. and Barnes, R. (2006). Producing place: a neo Schutzian perspective on the 'psychology of place.'J. Environ. Psychol., 26, 38-50.

[9] Aikawa, N., 2004. "An Historical Overview of the Preparation of the UNESCO International Convention for the Safeguarding of the Intangible Cultural Heritage" Museum International vol 56 (pp 137-149) Oxford: Blackwell Publishing. 